\title{
The Role of Institutional Research in Support of Strategic Planning
}

\author{
Heather Nel
}

\section{Introduction}

An academic revolution has taken place in higher education and the accelerated pace of change requires transformative, not evolutionary, approaches to university planning and decision-making. Higher education is increasingly challenged by "disruptive innovation" which is revolutionising our approach to education, which impacts on increasing accessibility, informing our delivery, and redefining the structure and function of learning environments, from virtual classrooms to "flipped" instruction (SCUP 2014:13).

In this context, there is a strong emphasis on institutional effectiveness and higher education is facing ever-increasing scrutiny to be accountable for results in achieving its purposes for public good (Santiago, Tremblay, Basri \& Arnal 2008:24). In a severely resource-constrained environment, the involvement of planners and institutional researchers in supporting the identification of new directions to respond to and shape transformative change has become crucial. This is accompanied by widespread recognition of the importance of user-friendly data analytics for accountability, performance assessment, and data-informed strategic planning (Norris \& Poulton 2010:1).

Government expectations as to what universities should deliver have also become more explicit and higher education has become unequivocally linked to economic progress and social well-being, including desirable outcomes such as poverty reduction, increased income equality, improved health, civic participation, good governance and the protection of human rights (Oketch, McCowan \& Schendel 2014:9). Requirements for strategic and performance-oriented management practices in universities have raised the prominence and significance of institutional research (IR) (Klemenčič et al. 2015:2). This is supported by Terenzini (1993:2-3) who asserts that the nature of IR and the role it plays continue to evolve as a consequence of advances in computing, the shifting budgetary climate, the increasing complexity and sophistication of decision making, and calls for increased institutional effectiveness. Calderon and Webber (2015:7-8) add that these drivers have resulted in a strengthened role for the practice of $I R$ and decision support within universities. In this regard, the role of IR is "...not only to collaboratively assist decision makers in navigating through these complexities but also for IR practitioners to be agents of change..." for the purposes of fostering institutional innovation and advancement. 
The research objective underpinning this chapter is to assess the role of IR in supporting strategic planning, organisational learning and renewal within a context of complexity. To address this question, the chapter will firstly briefly conceptualise IR and outline its various purposes, roles and functions. Flowing from this, attention will be devoted to exploring the role of IR in supporting strategic planning and decision-making through transforming data into knowledge that facilitates organisational learning. Thirdly, the tenets of the complexity approach will be deconstructed to provide a framework for understanding the role of IR in making sense of what Pascale (1999:91) refers to as "the edge of chaos". The chapter closes with a case study to illustrate the evolution of IR at a selected higher education institution in South Africa with an emphasis on the important role IR practitioners fulfil in supporting strategic planning.

\section{Conceptualising the role and functions of institutional research}

Peterson (1999:84) conceives of IR as research designed to generate information that examines the interface between a higher education institution and its environment to better understand how institutions adapt to complex challenges. In an often cited definition, Saupe (1981:1) describes IR "as the sum of all activities... which are used for the purposes of institutional planning, policy development, and decision making". The primary role of IR has changed over time from emphasising and requiring primarily descriptive statistics, fact books, and reporting, to more analysis and evaluation, both quantitative and qualitative (Volkwein 2008:8).

Volkwein $(1999,2008)$ and Serban (2002) note that IR is an evolving profession with a number of interdependent "faces". These "faces" of IR are diagrammatically depicted in Table 1 below (see also Chapter 1 ).

Table 1: Five "faces" of institutional research

\begin{tabular}{ll|l|}
$\begin{array}{l}\text { Organisational } \\
\text { role and culture }\end{array}$ & Formative and internal (for improvement) & Summative and external (for accountability) \\
\hline $\begin{array}{l}\text { Administrative } \\
\text { and institutional }\end{array}$ & $\begin{array}{l}\text { To describe the institution - IR as information } \\
\text { authority }\end{array}$ & $\begin{array}{l}\text { To present the best case - IR as } \\
\text { spin doctor }\end{array}$ \\
\hline $\begin{array}{l}\text { Academic and } \\
\text { professional }\end{array}$ & $\begin{array}{l}\text { To analyse alternatives - IR as } \\
\text { policy analyst }\end{array}$ & $\begin{array}{l}\text { To supply impartial evidence of } \\
\text { effectiveness - IR as scholar }\end{array}$ \\
\hline $\begin{array}{l}\text { Knowledge } \\
\text { management }\end{array}$ & $\begin{array}{l}\text { To gather and transform data into information and knowledge; to maintain an institutional repository } \\
\text { of data, information, and knowledge; and to facilitate the process of knowledge creation and sharing } \\
- \text { IR as knowledge manager }\end{array}$ \\
\hline
\end{tabular}

Source: Volkwein (1999:17, 2008:18) as adapted by Serban (2002:106)

Teodorescu (2006:78) cautions that IR is often consumed with responding to the information requirements of diverse external constituencies which leaves little time for reflection and yields minimal organisational learning. Consequently, the outcomes of IR tend to be skewed toward providing data and information rather than creating knowledge. Mamta (2012:1357) argues that effective IR requires the integration of data collected from various sources and its transformation into knowledge - depicted as the path to knowledge in Figure 1 below. The underlying premise is that IR plays a critical role in transforming data into information, 
and information into knowledge to advance organisational "wisdom" (IUQB 2008:19). As knowledge about universities becomes increasingly dispersed, IR practitioners serve as "boundary spanners" by assisting others to locate knowledge when it is generated in other parts of the university (Davenport \& Prusak 1998:4-5).

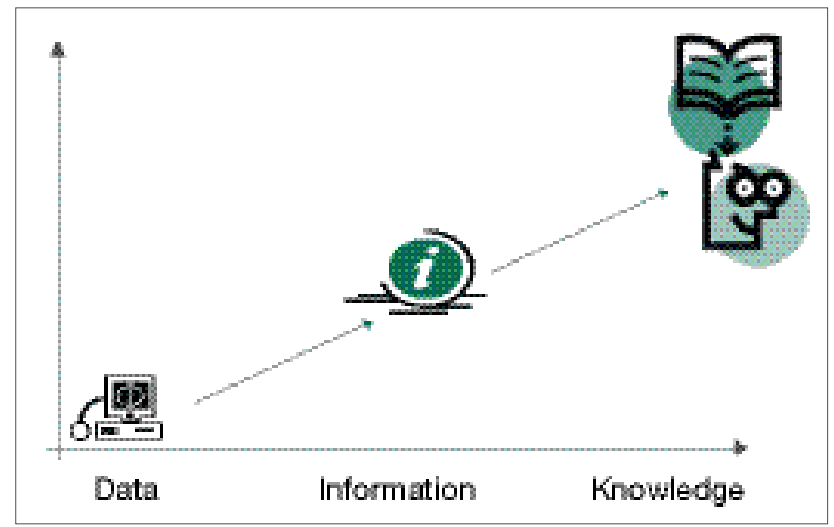

Figure 1: The path to knowledge

Source: IUQB 2008:19

IR practitioners transform data into information by adding value through contextualisation and by understanding for what purpose the information is required. Such knowledge is a fluid mix of framed experience, values, and expert insight that provides a framework for evaluating and incorporating new experiences and information. IR practitioners need to appreciate that an organisation's most important knowledge often resides in individuals as tacit knowledge that relates to experience and intuition. This needs to be tapped into in addition to explicit knowledge that is readily documented and communicable (Clarke \& Rollo 2001:209).

In contrast to the hierarchical view of knowledge as a higher form of information or data, Makani (2015:350-351) views the relationship between data, information and knowledge as constituting a continuous sequence of activities or tasks that are interwoven. As illustrated in Figure 2, action is defined as the ability to respond to knowledge and thereby make the best use of what is known. The gaps between information and knowledge and between knowledge and action can be referred to as the "thinking gap; know-what" and "knowingdoing gap; know-how" respectively. These gaps denote the IR practitioner's ability or inability to transform existing data, information and knowledge into meaningful action. This is referred to as "know-how" that embraces the ability to put "know-what" into practice. The practice-based perspective presents knowledge and knowing as inseparable from human activity and practice (Jashapara 2011). 


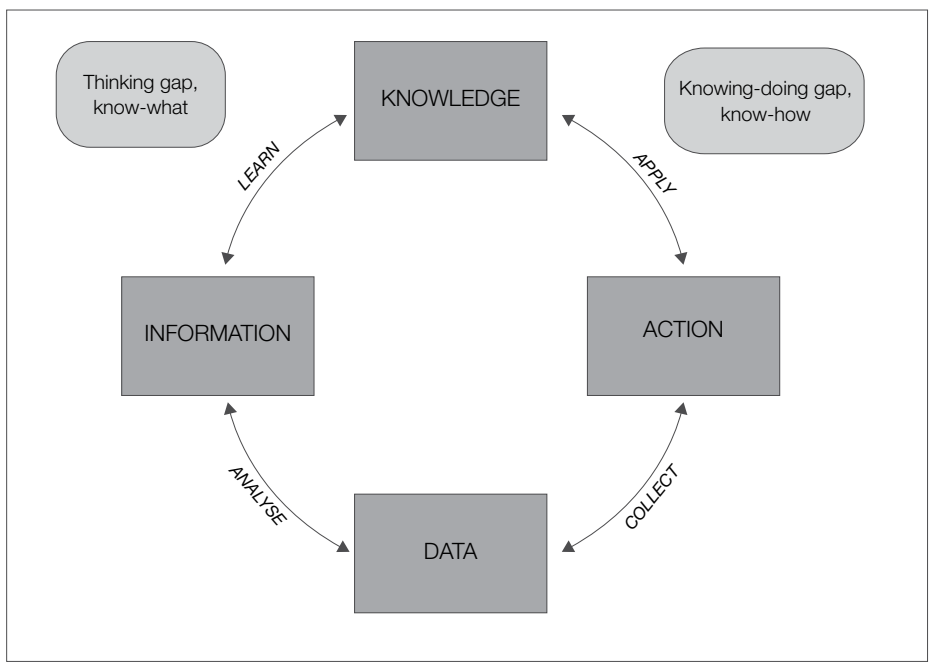

Figure 2: Relationship between data, information, knowledge and action

Source: Adapted from Musimwa-Makani (2012)

Terenzini (1993:3-6) is a proponent of viewing the role of IR as organisational intelligence in three mutually dependent, but distinct, forms or levels, technical and analytical intelligence, issues intelligence and contextual intelligence (see Chapter 1). Figure 3 below highlights the need for IR practitioners to embrace all three levels of organisational intelligence, given that they are mutually dependent and supportive.

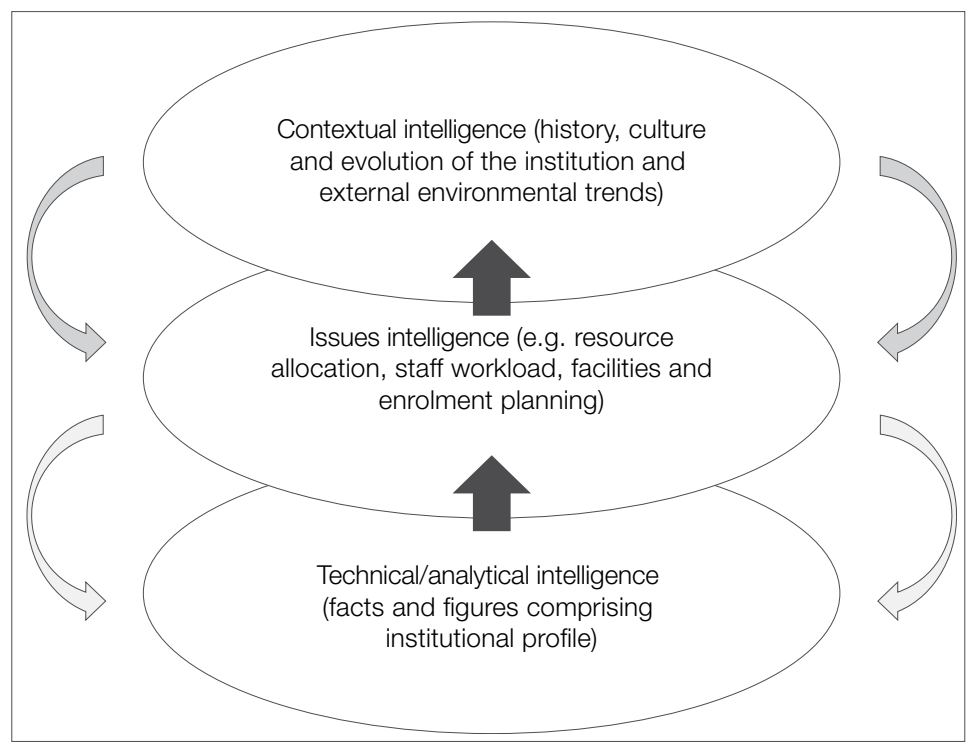

Figure 3: Institutional research and levels of organisational intelligence Source: Terenzini (1999) adapted by Nel (2015) 
IR practitioners who contribute to generating organisational intelligence have the potential to position universities as learning organisations where knowledge contributes to continuous performance enhancement. The role of IR in supporting strategic planning will be elaborated on in the next section.

\section{The role of institutional research in supporting strategic planning}

The emergence of strategic planning in higher education has been prompted by pressures from governments through performance-based funding models, quality assurance and accreditation regimes, and increased global competition (Klemenčič et al. 2015:8). This gave rise to the application of strategic planning as a tool to respond proactively to the challenges confronting higher education institutions (Hinton 2012:7).

Against this backdrop, Shawyun (2011:5-7) writes that there are three basic questions that strategic planning processes seek to address, namely, Where we are now and where are we going? This should address the institution's current and past performance and capabilities based on an analysis of both the internal and external environments. The next question is, Where do we want to go or where could we be going? This question should address where the institution wants to stake out a future position in the educational landscape. Lastly, How do we get there? This question should address the resources and capabilities that the institution needs to achieve its desired strategic positioning and outcomes.

Lapin (2004:106) adds that strategic planning emphasises that strategic planning is usually undertaken in response to internal imperatives to ensure that the university operates as efficiently and effectively as possible. However, he argues that it is even more important to position the university in relation to its external environment - political, economic, social, technological and environmental - to respond proactively to trends, events, emerging issues and "wild cards" that will impact on their future.

Shawyun's three questions clearly indicate a role for IR in all the phases of strategic planning. Once a plan is complete, however, IR also contributes to comparing desired and actual performance. It also provides feedback to explain deviations in achieving targets, should such deviations occur. This requires that the plan includes measurable criteria for success and clear accountability for progress or lack of progress (Hanover 2013:10). This is supported by Hollowell et al. (2010:69) who assert that planning must include a sustained assessment of progress toward goals and objectives to provide demonstrable evidence that the university has successfully achieved what it set out to do. Stated simply, strategic planning is a journey that begins best when appropriate quantitative and qualitative data are transformed into actionable information (Voorhees 2008:79). Plans fail for all sorts of reasons, but breakdowns in the planning process can often be attributed to shortcomings in monitoring and evaluating a plan's progress in achieving its desired outcomes (Rutgers 2010:5).

Dooris et al. (2002:10) add that strategic planning - if wisely used - can be a powerful tool to assist a university to listen to its constituencies, to encourage the emergence of innovative ideas, to recognise opportunities, to make decisions supported by evidence, and to strive towards a shared mission and vision. Relatively recent conceptions of strategic planning increasingly recognise that university leaders need to embrace flexibility, agility, 
and inventiveness through a focus on imaginative strategic thinking as opposed to linear, causal analysis (Mintzberg 1994:107).

Chaffee and Tierney (1988) explain that the transformation from a linear ("meet the budget") to an expressive ("create the future") planning mode, is predicated on a university's ability to maintain a dynamic equilibrium between its culture, its leadership, and the continuous communication of values. As planning evolves, there are differences in the reactive versus proactive nature of IR activities and their relevance to decision making for the future. This progression assumes that meaningful analyses are built on a sound understanding of the data and that insightful syntheses will incorporate both intuition and rigorous analysis. Linear planning relies on historical trends, the status quo, and a static view of the future. Expressive planning relates external variables to the university's culture and values and IR practitioners are required to synthesise separately conducted analyses within an interpretive strategic framework. There is greater emphasis on qualitative analysis to counterbalance the quantitative and rational bias embedded in linear planning processes.

Dressler (1981:254-255) argues that, if universities are to maintain strategic flexibility, innovation must be encouraged and there must be a sensitivity and a responsiveness to new circumstances external to the institution. The achievement of strategic flexibility requires a constant review of planning and those who do it. The linear model of planning has come under heavy criticism, primarily because it often neglects the complex issues that usually come to the fore during the execution phase of the plans. Research has shown that the most successful organisations place significant emphasis on experience and the implicit knowledge accumulated within the organisation, as well as their ability to improvise (Zechlin 2010).

This notion is particularly well developed in Mintzberg's work (1994:24-25) where he explains that intended strategies can sometimes be implemented later as deliberate strategies. Meanwhile, plans that were identified during the initial planning phases, but remained unrealised, must be left aside. He refers to "emergent" strategies that develop as a result of innovations within, and external to, the system. Realised strategies are based on the sum of all of these approaches.

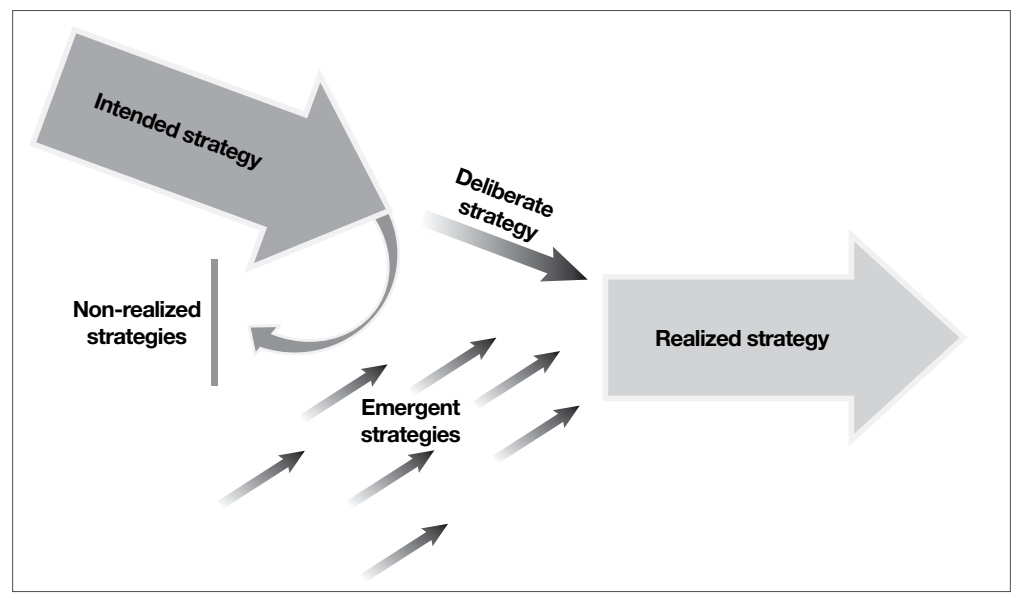

Figure 4: Mintzberg's deliberate and emergent strategies

Source: Adapted from Mintzberg 1994:24 
According to Zechlin (2010:7), emergent models of strategy development require that university leadership has to be able to cope with ambivalence and contradiction by attaching increased value to observation and reflection. The role of leadership entails developing a broad strategic framework that allows for self-determined actions by organisational subsystems. The reciprocity between strategic thinking and action are reinforced through frequent and repeated loops of reflection on the process. Strategic planning shifts to becoming a reflective, learning cycle that feeds back into the organisation, where the decisions that are made remain alterable and opportunities for emergent strategies to evolve are opened.

In complex adaptive systems (CAS), strategic planning should be seen as an emergent, interactive dynamic - a complex interplay from which a collective impetus for action and change emerges when heterogeneous agents interact in networks in ways that produce new patterns of behaviour or modes of operating. The complexity approach focuses on identifying and exploring the strategies and behaviours that foster creativity, learning, and adaptability (Uhl-Bien et al. 2007:303).

Globally, higher education institutions are being called upon to navigate increasingly complex and uncertain terrains because of phenomena such as globalisation, international ranking, shrinking government funding, and demands to widen access to marginalised groups. It is in this context that the role of IR practitioners in supporting emergent and creative modes of planning becomes important. This will be explored more fully in the next section.

\section{A complexity approach to institutional research and strategic planning}

It is widely recognised that successful organisations are adaptive and capable of developing unexpectedly creative solutions to problems (Amagoh 2008). From a complexity perspective, organisations as systems can be observed in two states, stable and unstable. The most interesting behaviour occurs on the cusp of stability and instability, or what Pascale (1999) refers to as the "edge of chaos". A complexity perspective embraces non-causal, nonlinear interpretations of systems with the awareness that the collective activity of the units within the system is not fully explained by their sum, and that they may produce emergent properties. These properties feature spontaneous, unpredictable and self-organised patterns and behaviours (Smith 2005).

When it is at the edge of instability, a system is far easier to change because small actions of agents within the system can escalate into major outcomes. The application of the complexity approach to organisational life leads to the proposition that changeable organisations are those in which the informal feedback networks are richly connected and sustained away from equilibrium in a state of bounded instability. The disorderly dynamics of contradiction, conflict, tension, and dialogue provide the driving force for emergent patterns of behavior (Stacey 1995). A complexity approach emphasises mindfulness, mission-based and valuesbased decisions, fostering relationships, and constructing possibilities that contribute to an organisation's resilience. A strategic plan itself is not a blueprint for a future desired state, but prepares an organisation to be more mindful of, and responsive to, the constant changes and possibilities emerging from its environment (Prewitt et al. 2012). In this context, IR 
practitioners fulfil an important role in understanding that strategic planning is a dynamic process the institution can use to deal with an unpredictable reality (Hilburt-Davis 2000).

Hummelbrunner and Jones (2013:5-7) outline three core principles that form the basis of planning approaches that are suited to increasingly complex contexts. Firstly, there is a need to move from static to dynamic and iterative planning where plans are regarded as hypotheses about future developments. Secondly, a transition from prescriptive to flexible planning modes is required whereby leadership formulates clear principles for action which guide implementation while encouraging adaptive responses. Thirdly, embracing diversified planning requires working with a 'hierarchy of plans' which stimulates the self-organisational capacities of each level and improves ownership. In a multi-level planning structure, each level should carry out its own operational planning and, at the same time, provide a strategic frame for the level beneath.

Organisational learning can thus be conceived of as a principal means of achieving strategic renewal. Renewal requires that organisations explore and learn new ways of knowing, doing and being, while concurrently exploiting what they have already learned. This poses the challenge for IR practitioners to be flexible in their choice of issues to analyse and the methods that are applied to generate knowledge in support of strategic renewal. This will be explored in more depth in the next section with reference to the role of IR in supporting strategic planning and organisational renewal.

\section{Exploring the role of institutional research in supporting strategic planning and organisational renewal at Nelson Mandela Metropolitan University}

The primary research questions underpinning this study have been partially addressed through an exposition of pertinent conceptual and theoretical frameworks, such as Volkwein's and Serban's faces of IR, Terenzini's levels of organisational intelligence, as well as the complexity approach to organisational learning and renewal. This part of the chapter consists of a reflective case study with a special emphasis on how the tenets of these theoretical frameworks can be applied to IR and strategic planning at a particular South African higher education institution.

This case study focused on the role of IR in supporting strategic planning and organisational renewal at a selected higher education institution in South Africa. In so doing, I have sought to apply the relevant theoretical underpinnings to facilitate the exploration of contextual conditions which pertain to the practice of IR within a complex higher education landscape where there is a need to implement data-informed decision making and planning processes. This enables me to assess critically the extent to which the office responsible for strategic planning and IR at the selected higher education institution has contributed to strategic planning and organisational renewal, the challenges encountered, and possible future directions to explore.

To address the research questions, I have relied on insider experiences of, and immersion in, the field of higher education strategic planning and institutional research for the past ten 
years (2005-2015). The challenge was to be aware of the potential for bias which required a reflexive approach. I drew upon auto-ethnography as one of the few insider research methods available for 'studying one's own culture and oneself as part of that culture' (Patton 2002:85).

Observing and participating are integral to understanding the breadth and complexities of the human experience (Mack et al. 2005:14). In this case, participant observation assisted the author to form an in-depth understanding of the challenges and benefits associated with strategic planning and the roles that IR can fulfil in supporting organisational renewal within a context of complexity.

\section{An historical overview of Nelson Mandela Metropolitan University}

Nelson Mandela Metropolitan University (NMMU) is one of six comprehensive universities in South Africa established through the incorporation of the Port Elizabeth campus of Vista University into the University of Port Elizabeth (UPE) in January 2004 and the subsequent merger of the Port Elizabeth Technikon and UPE in January 2005. The processes associated with integrating three sets of organisational structures, systems, policies, and cultures, along with finalising the governance framework and mapping the strategic direction of the University constituted early challenges for the newly merged university. This was accompanied by a strong focus on securing the university's financial viability through the development of the university's institutional operating plan (IOP) which was submitted to the national Department of Education in 2006 to qualify for recapitalisation and mergerrelated funding.

Ten years after the merger, in 2015, NMMU had a total student headcount enrolment of 27664 and its 2300 permanent staff members were distributed across five campuses in Port Elizabeth and another one in George. Its vision is to be a dynamic, African university recognised for its leadership in generating cutting-edge knowledge for a sustainable future. Given its distinctive niche as a comprehensive university, NMMU's mission is to provide access to diverse educational opportunities through a wide range of general formative and vocational, career-focused programmes across various fields of study. To achieve this vision and mission, a dedicated planning and IR capability was required to support university decision makers in implementing evidence-based policies, strategies and practices.

\section{The evolution of IR in support of planning and organisational renewal at NMMU}

As an acknowledgment of the significant organisational renewal interventions that were required as a result of the merger, the post-merger restructuring made provision for the establishment of a central office responsible for four functions, (a) supporting strategic and academic planning processes at institutional and divisional/faculty levels; (b) conducting data analytics, institutional surveys and selected research studies in support of decisionmaking and planning; (c) monitoring and evaluating institutional effectiveness; and (d) coordinating reporting to internal and external stakeholders. Despite undergoing some structural adaptations since 2005, the Office for Institutional Planning (OIP) has retained the oversight of these functions and is optimally positioned to impact on planning, policy development since it is situated within the Office of the Vice Chancellor, and its Senior 
Director is represented on key senior management decision-making structures. The establishment of the OIP was thus a direct response to the need of the merged institution for evidence-based, analytical decision support to key academic and administrative decisionmakers at various levels.

NMMU benefitted from the organisational renewal and innovation that was unleashed through the bounded instability of the merger processes. The university leadership was able to analyse and retain good practices inherited through the merger whilst grasping the opportunity, where necessary, to develop entirely new approaches that aligned with its strategic intentions. During this period, extensive IR studies were conducted, using multiple methods, to inform important planning processes. These included crafting the vision, mission, values and strategic priorities for the newly merged university; allocating faculties and administrative divisions to various campuses in a multi-campus context; preparing the Institutional Operating Plan (IOP) to secure the financial sustainability of the university; and outlining the principles and criteria for restructuring and integrating academic and administrative structures.

A crucial dimension of the strategic positioning of NMMU as a comprehensive university was the development of a consolidated academic qualifications and programme profile. From 2006 to 2009, a collaborative research project, funded by the South Africa Norway Tertiary Education Development Programme (SANTED), was undertaken by NMMU and the University of Johannesburg to develop a new academic qualifications structure and programme profile that would enhance access and articulation between various qualification types. As a result of intensive research conducted by curriculum experts, a conceptual framework relating to programme and curriculum models was developed for the two universities to inform the development of access, articulation, progression, and transfer pathways within and between qualifications in cognate fields of study.

The crafting of the ten-year Vision 2020 strategic plan was initiated in 2008 and was developed through a highly consultative process. Formulating Vision 2020 provided a unique opportunity for the university community and its stakeholders to define NMMU's distinctive academic purpose and identity and to determine strategic priorities that would secure the long-term sustainability of the institution. As part of consultations with key internal and external stakeholders, focus group and in-depth interviews were conducted to spark futurefocused dialogue in respect of three key questions, namely: What kind of university would you like NMMU to be by 2020? What will make it possible for NMMU to achieve this? What are the key uncertainties in the external environment that could impact on NMMU achieving this?

Responses to these questions were analysed and the emerging themes formed the basis for crafting NMMU's Vision 2020 strategic plan. Representative task teams were convened to inform the process of developing a detailed institutional strategic plan. The plan included strategic goals, objectives, outputs and key performance indicators to monitor progress towards achieving NMMU's desired future state. This strategic planning process was underpinned by ongoing, thorough environmental scanning as well as various IR studies of the strengths, challenges, opportunities and threats confronting NMMU. 
As part of co-creating a transformative institutional culture and unifying organisational identity at NMMU, the Vice Chancellor (since 2008), Professor Derrick Swartz, conceptualised and allocated considerable institutional resources to implement a pioneering "institutional culture enlivening process" at all levels of the university. This innovative organisational development process commenced in 2014 to encourage staff and students to grapple collectively with important questions of transformation and the implications of living the values and principles contained in Vision 2020. This encompassing process for culture change touches on every aspect of university life, including curriculum and pedagogical transformation, diversifying staff and student demographic profiles, encouraging values-aligned behaviour, engaging in difficult dialogues about inequality and social justice, promoting sustainability, and reengineering institutional systems and processes.

As part of this intervention, the IR practitioners within OIP have been challenged to think afresh about the frame of reference and methodologies to be applied monitoring, evaluating and advising management as it pertains to the pace and depth of organisational renewal and transformation. Peterson (1999:84) correctly asserts that an institution undergoing extensive transformation needs to mount efforts to assess both the readiness and capacity for institutional redesign. In this regard, it is important that IR contributes in qualitatively meaningful ways to organisational intelligence by ensuring that fundamentally transformative renewal processes are not reduced merely to quantitative data and logical framework models. A complexity approach requires that the rich narratives and experiences of various stakeholders are captured and interpreted to promote learning and reflection. This constitutes a particular focus for OIP going forward and will necessitate a paradigm shift that contributes to understanding the transformation journey in deeper, more contextually informed ways.

As indicated by Volkwein (2011:11), the classic Janusian challenge for most IR practitioners is to resolve the potential tension between their internal and external roles. He suggests that this should be viewed as distinguishing between inspirational and pragmatic orientations - doing something because you want to versus doing something because you have to. The inspirational orientation aims to enhance institutional effectiveness to achieve an organisational climate characterised by ongoing reflection and continuous improvement. The pragmatic orientation recognises the need to be accountable to external stakeholders such as regulators and funders to position the university strategically and to secure funding. This constitutes a particular challenge for the OIP since the limited IR capacity is largely consumed by responding to external regulatory and reporting requirements which leaves little time for the scholarly research that facilitates organisational learning and creativity. This seems to be a problem at most South African higher education institutions (see Chapter 4).

Roper and Pettit (2002:14) note that, despite an emphasis on learning and knowledge creation, IR practitioners often feel trapped in a vicious cycle. As organisations learn by doing, real learning becomes even more important. Increased complexity, however, intensifies demands on staff, resulting in even less time for reflection and learning. When and how can this vicious cycle be transformed into a virtuous one of reflective practice? This will be explored in more depth in the next section. 


\section{Reviewing the role of IR and strategic planning at NMMU from a complexity perspective}

Improved planning in the face of complexity relies on more than awareness and knowledge of tools. Enabling leadership fosters interactions of complex organisational systems with environmental dynamics. Uhl-Bien et al. (2007:303) argue that "creativity and learning occur when emergence forms a previously unknown solution to a problem or creates a new, unanticipated outcome (i.e. adaptive change)."

Planning practices that foster organisational learning and renewal embrace adaptive planning approaches that are responsive to contextual changes and focus on providing feedback on lessons learned from implementation (Hummelbrunner \& Jones 2013:9). A key question worth framing is: Does planning enable or inhibit non-linear emergence? The short answer is that planning for creativity should be a continuous learning process to adjust for the changes and unknowns that are certain to arise. The complexity lessons for those ordinarily engaged in strategic foresight and IR are twofold, namely, that responsiveness must take precedence over preparation, and that it is important to recognise that the "edge of chaos" can provide a platform for the emergence of innovative ways of addressing complex organisational challenges. In essence, the task of IR practitioners and planners in this context is to cultivate an environment in which innovation and creativity are likely to emerge (Smith 2005:26).

Peterson (1999:84) concurs by asserting that IR has flourished as an institutional function because it has contributed to the adaptive capacity of institutions and has played a major role in fostering and assisting institutional change. In the years ahead, the role of IR will be to assist higher education institutions to address changing conditions that require not just improved effectiveness, but institutional redesign and transformation.

At NMMU, planning officers and IR practitioners have been grappling with the need to think afresh about their role in enabling creativity and the emergence of strategies to enable the university to adapt to a rapidly changing environment, particularly within organisational sub-systems such as faculties and administrative divisions. The complexity approach views organisational change as comprising a non-linear, integrated, and socially embedded process affected by a variety of causes and concepts. As the complexity of a system increases, the ability to understand and use information to plan and predict strategic outcomes becomes more difficult. The complexity theory paradigm rejects the mechanistic ontological models, which assume linear causality between events and effects. Systems that operate near a threshold of instability are those that tend to exhibit creativity and produce innovative behaviours at the level of the whole system (Amagoh 2008:6).

In this regard, Stacey $(1995: 493)$ points out that:

"If innovative organizations are nonlinear feed-back systems operating far from equilibrium then reductionist approaches to researching them are likely to produce seriously misleading conclusions. Cross-sectional tests of linear causal hypothesis will simply be interesting exercises in hindsight. Instead, research will have to focus on the meanings of the irregular patterns of behavior observed and on reasoning about the kind of system those patterns are being generated by. 
Instead of looking for causes and effects it is necessary to look for patterns and their systemic implications."

This will require that IR practitioners need to create optimal conditions for organisational learning and renewal by moving beyond Terenzini's technical and issues intelligence to embrace contextual intelligence in an effort better to understand complex challenges and opportunities confronting their universities and to contribute meaningfully to flexible and adaptive planning approaches. This speaks to the development of "organisational savvy and wisdom" (Terenzini 1999:25), especially in terms of the complex challenges confronting higher education nationally and globally.

NMMU's OIP functions effectively as the hub of technical/analytical intelligence for the university and is responsible for providing reliable, accurate institutional data and information timeously to internal and external stakeholders. Examples of data that are continuously monitored include enrolment patterns, student staff ratios, retention rates, graduate outcomes, financial viability, and space utilisation patterns. These data are converted to information and are accessible to decision makers through a homegrown, web-enabled Business Intelligence (BI) system called IntelliWeb. Such information is critical to planning and institutional effectiveness processes, and enables the OIP to act as both a knowledge manager and an information authority. Using this system, reliable information is centrally accessible to users through various reporting tools and dashboards. Additionally, the system facilitates consistent data interpretations and reporting standards, and helps to maintain data integrity across the university.

As depicted in Figure 5 below, the OIP has developed an institutional monitoring, evaluation and reporting framework in terms of which institutional performance is systematically monitored and reported on. This serves to ensure that NMMU's strategic directional statements are translated into action at all levels of the institution and that Council is provided with comprehensive quarterly performance review reports which outline progress, or the lack of it, in respect of strategy implementation. This comprehensive M\&E framework is underpinned by indicators that assess institutional effectiveness in terms of four key pillars, namely, (a) NMMU's strategic positioning and identity as a comprehensive university; (b) teaching and learning excellence; (c) the productivity and impact of research and engagement; and (d) organisational capability and sustainability. These pillars are monitored and evaluated using student success as a lens; in other words, the contribution of the core missions of teaching and learning, research and engagement are evaluated through IR to assess the impact they have on enhancing student success. This ensures that IR is focused and targeted to provide rich information for the purposes of decision support, planning and resource allocation. 


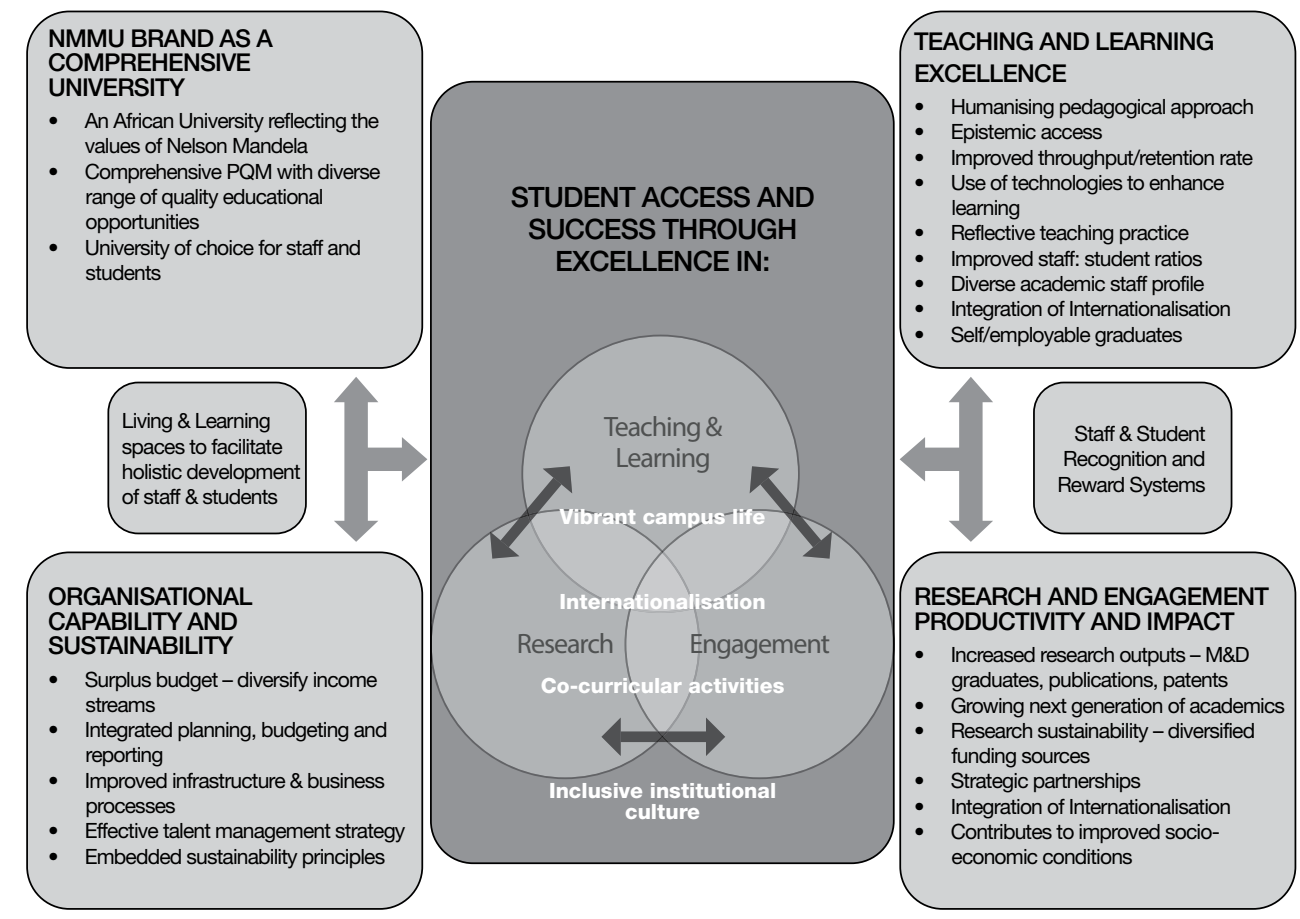

Figure 5: NMMU monitoring and evaluation framework

McChesney et al. (2012:32) refer to "wildly important goals" as those strategically significant goals that need to be systematically tracked through the use of a compelling scoreboard. In the NMMU context, as is evident from Figure 5 above, holistic student success is an example of a wildly important goal and the monitoring, evaluation and IR endeavours are largely focused on tracking multi-dimensional indicators of student success. Interestingly, Volkwein (2011:19) advocates for the assessment of student performance at critical points during the educational process to enable higher education institutions to build a culture of evidence and to become more effective learning organisations.

Student success is monitored at NMMU through ongoing data analytics and cyclical IR studies, including surveys such as the South African Survey of Student Engagement (SASSE) and the Graduate Destinations Survey. NMMU has also been selected as one of five higher education institutions in South Africa to participate in the Kresge-funded Siyaphumelela (it means "together we succeed") project over a four-year period to design and implement a data analytics tracking system for the early identification of academically vulnerable students. The challenge is to ensure that the narratives and personal experiences of students that lie underneath the quantitative data are adequately surfaced through appropriate research methodologies (see Chapter 13).

According to Glover (2009:1), universities that invest in integrated systems to collect and effectively provide data for interpretation are far better positioned to deepen their understanding of student progression and identify strategies for improving student success. This is supported by Williford (2009:5) who notes that, as advocates for student success, 
IR practitioners can help the university community to understand students' characteristics and needs better, with a view to enhancing the visibility of student attrition and retention challenges, and thus reinforcing best practices. Through systematic data analytics and survey research on incoming students, student experiences, and graduate destinations, the OIP is able to evaluate critical dimensions of student success - thereby fulfilling Volkwein's role of IR as researcher or scholar.

By being a proactive provider of organisational intelligence, IR practitioners assist the university leadership to be adaptive and responsive thereby benefiting both the institution and the profession. (Peterson 1999:103). In leveraging off the data and information gathered for the purposes of technical and issues intelligence, it is evident that the Office responsible for IR at NMMU is well positioned to fulfil a scholarly knowledge-management role in supporting planning and quality improvement interventions at various levels of the university. A perrenial challenge for IR practitioners is, however, to enhance the extent to which the findings of IR studies positively impact on practice, and ultimately, on student outcomes. This provides scope for strategic experimentation in exploring innovative dissemination strategies which are customised to the particular needs of various stakeholders in a quest to ensure that the trends emerging from data analytics and IR studies are more readily engaged with and responded to.

\section{Conclusion}

By referring to theories of $I R$, planning, complexity and organisational change as a frame of reference, this chapter analysed and reflected on the role of IR and planning within a dynamic and unpredictable higher education context. This was complemented by the use of a case study whereby the roles of IR at a selected higher education institution were discussed in-depth using a participant observation method.

This chapter has pointed to the evolution of IR as a practice in terms of its important role in supporting continuous organisational renewal and improvement. It is clear that IR practitioners have gone beyond the collection and analysis of data for information generation and have taken on the role of scholars and knowledge managers who can harness creative emergence and learning for the purposes of assisting their universities to thrive within a context of ever-increasing complexity.

\section{References}

Amagoh, F. 2008. Perspectives on Organisational Change: Systems and Complexity Theories, The Innovation Journal: The Public Sector Innovation Journal, 13 (3):1-14.

Calderon, A.J. and Webber, K.L. 2015. "Institutional Research, Planning, and Decision Support in Higher Education Today", in K.L. Webber and A.J. Calderon (eds.). Institutional Research and Planning in Higher Education:
Global Contexts and Themes, New York, Routledge, pp. 3-15.

Chaffee, E.E. and Tierney, W.G. 1988. Collegiate Culture and Leadership Strategies. New York: Macmillan.

Chan, S.S. 1993. Changing roles of institutional research in strategic management, Research in Higher Education, 34 (5):533-549. http://dx.doi. org/10.1007/BF00991918 
Clarke, T. and Rollo, C. 2001."Corporate initiatives in knowledge management", Education + Training, 43 (4/5):206 214, Access online at http://dx.doi. org/10.1108/00400910110399201

Davenport, T. and Prusak, L. 1998. Working Knowledge: How Organisations Manage What They Know. Boston: Harvard Business School Press. Excerpt available online at http://www.kushima.org/is/wpcontent/uploads/2013/09/Davenport_ know.pdf

Dooris, M.J., Kelley, J.M. and Trainer, J.F. 2002. Strategic Planning in Higher Education, New Directions for Institutional Research, 116, Fall 2002.

Glover, R. 2009. Strengthening Institutional Research and Information Technology Capacity through Achieving the Dream: Principles and Practices of Student Success, Lumina Foundation for Education, pp.1-10. Access online at http://www.achievingthedream.org/docs/ guides/ATD_IR_IT.pdf PMid:21814634 PMCid:PMC̄3147290

Hanover Research. 2013. Strategic Planning in Higher Education - Best Practices and Benchmarking, Washington, DC. Access online at http://www.hanoverresearch. $\mathrm{com} / \mathrm{media} /$ Strategic-Planning-in-HigherEducation-\%E2\%80\%93-Best-Practicesand-Benchmarking.pdf

Hilburt-Davis, J. 2000. Learning from Complexity: Is Strategic Planning Obsolete? Practice Paper, The Family Firm Institute:141-144. Access online at http://www.familybusinessconsulting. com/resources/strategic_planning.pdf

Hinton, K.E. 2012. A Practical Guide to Strategic Planning in Higher Education. Society for College and University Planning.

Hollowell, D. Middaugh, M. and Sibolski, E. 2010. Integrating Higher Education Planning and Assessment: A Practical Guide Digital Version, Society for College and University Planning.

Hummelbrunner, R. and Jones, H. 2013. A guide for planning and strategy development in the face of complexity. Overseas Development Institute Background Note, March 2013. pp. 1-12.
Irish Universities Quality Board (IUQB). 2008. Good Practice for Institutional Research in Irish Higher Education. National Guidelines.

Lapin, J.D. 2004. Using External Environmental Scanning and Forecasting to Improve Strategic Planning, Journal of Applied Research in the Community College, 11 (2):105-113. Access online at http://www.kvcc.me.edu/ CMSContent/Departments/Institutional Assessment $/ 2004 \% 20$ Env\%20 Scanning\%20and\%20Forcasting\%20 to $\% 20$ improve $\% 20$ strategic $\% 20$ planning\%20-\%20Lapin.pdf

Klemenčič, M., Šćukanec, N. and Komljenovič, J. 2015. Decision support issues in Central and Eastern Europe. In K.L. Webber and A.J. Calderon (eds.). Institutional Research and Planning in Higher Education: Global Themes and Context. New York: Routledge. Access online at http://www.routledge.com/ books/details/9781138021433/

Mack, N., Woodsong, C., Macqueen, K.M., Guest, G. and Namey, E. 2005. Qualitative Research Methods: A Data Collector's Field Guide, Module 2: Participant Observation, North Carolina: Family Health International, Access online at http://www.fhi360. org/sites/default/files/media/documents/ Qualitative\%20Research\%20 Methods\%20-\%20A\%20Data\%20 Collector\%27s\%20Field\%20Guide.pdf

Makani, J. 2015. Knowledge management, research data management, and university scholarship, VINE, 45 (3):344359. http://dx.doi.org/10.1108/VINE-072014-0047

Mamta, B. 2012. Institutional Knowledge to Institutional Intelligence: A Data Mining Enabled Knowledge Management Approach. International Journal of Computational Engineering Research 2 (5):1356-1360.

McChesney, C., Covey, S. and Huling, J. 2012. The 4 Disciplines of Execution: Achieving Your Wildly Important Goals. Franklin Covey Co, Access online at http://www.midlandsonestop.org/public docs/The\%204\%20Disciplines\%20of\%2 $\overline{0}$ Execution.pdf

Mintzberg, H. 1994. The Rise and Fall of Strategic Planning: Reconceiving Roles 
for Planning, Plans, Planners, New York: Simon and Schuster. PMid:8089715

Musimwa-Makani, J. 2012. Knowledge management in knowledge-intensive organisations: an investigation of factors influencing choices of knowledge management systems. Doctoral Thesis, Dalhousie University.

Norris, D.M. and Nick L. Poulton, N.L. 2010. A Guide to Planning for Change. Society for College and University Planning. 2010. Access online at https://www2. cortland.edu/dotAsset/90d13b15-af024732-a13f-0b2c5f81b958.pdf

Oketch, M. McCowan, T. and Schendel, R. 2014. The Impact of Tertiary Education on Development, t: A Rigorous Literature Review. Department for International Development. Access online at https://eppi.ioe.ac.uk/cms/ Portals/0/PDF\%20reviews\%20and\%20 summaries/Tertiary\%20education $\% 20$ 2014\%200ketch\%20report. pdf?ver=2014-06-24-161044-887

Pascale, R. 1999. 'Surfing the edge of chaos.' Sloan Management Review. 40 (3):83-94. Access online at https://learning-change. wikispaces.com/file/view/Pascale+R++ Surfing.pdf

Patton, Michael Quinn. 2002. Qualitative Research \& Evaluation Methods. 3rd ed. Thousand Oaks, CA: Sage Publications.

Peterson, M. W. 1999. The Role of Institutional Research: From Improvement to Redesign, New Directions for Institutional Research. 104:83-103. Access online at http:// onlinelibrary.wiley.com/doi/10.1002/ ir. 10408/pdf

Prewitt, J.E., Weil, R. and McClure, A.Q. 2012. A Complex Adaptive Systems Approach to Strategic Planning, Asian Journal of Business and Management Sciences. 1 (11):94-99. Access online at http://www.ajbms.org/articlepdf/ ajbms201211i11111.pdf

Roper, L. and Pettit, J. 2002. Development and the Learning Organisation: An Introduction, Development in Practice 12:258-71. Access online at http:// www.developmentinpractice.org/ sites/developmentinpractice.org/files/ LearningOrgFullTextEN.pdf http://dx.doi. org/10.1080/0961450220149654
Rutgers 2010. Strategic Planning in Higher Education: A Guide for Leaders, Centre for Organisational Development and Leadership, Rutgers, The State University of New Jersey. Access online at https:// ddq.nu.edu.sa/ddq1/files/35.pdf

Santiago, P. Tremblay, K. Basri, E. and Arnal, E. 2008. Tertiary Education for the Knowledge Society, Volume 1, Special Features: Governance, Funding, Quality, OECD Publishing, Paris. Access online at www.oecd.org/edu/tertiary/review

Saupe, J.L. 1990. The Functions of Institutional Research. 2nd Edition. Tallahassee, FL: Association for Institutional Research.

Serban, A. 2002. Knowledge Management: The 'Fifth Face' of Institutional Research. New Directions for Institutional Research. 113:105-111. http://dx.doi.org/10.1002/ ir. 40

Smith, A.C.T. 2005. Complexity theory for organisational futures studies. Foresight 7 (3):22-30. http://dx.doi. org/10.1108/14636680510601959

Society for College and University Planning. 2014. SCUP Academy Report 2014. Access online at https://scup-frameworkproduction.s3.amazonaws.com/cms/ asset version/file/11/24/112434.pd $\mathrm{f}$ ?AWSAccessKeyld =AKIAJYNXXD GIQEC64CEQ\&Expires=1448528 $524 \&$ Signature $=0$ KaFYF82jtd8FS EyFSpLczNMojQ\%3D\&responsecontent-disposition =inline $\% 3 \mathrm{~B} \% 20$ filename\%3D\%22SCUPAcademy Report2014.pdf\%22\& response-contenttype =applicati on $\% 2 \mathrm{Fpdf}$

Stacey, R.D. 1995. The Science of Complexity: An Alternative Perspective for Strategic Change Processes. Strategic Management Journal. 16 (6):477495. Access online at http://www. jstor.org/stable/2486790 http://dx.doi. org/10.1002/smj.4250160606

Teodorescu, D. 2006 Institutional researchers as knowledge managers in universities: Envisioning new roles for the IR profession, Tertiary Education and Management. 12 (1):75-88. http://dx.doi. org/10.1080/13583883.2006.9967161

Terenzini, P. 1993. On the Nature of Institutional Research and the Knowledge and Skills it Requires. Research in Higher 
Education. 34 (1):1-10. http://dx.doi. org/10.1007/BF00991859

Uhl-Bien, M., Marion, R. and McKelvey, B. 2007. Complexity Leadership Theory: Shifting leadership from the industrial age to the knowledge era. Leadership Institute Faculty Publications. Paper 18. Access online at http://digitalcommons. unl.edu/leadershipfacpub/18

Volkwein, J. F. 1999. The Four Faces of Institutional Research. New Directions for Institutional Research. 104:9-20. http:// dx.doi.org/10.1002/ir.10401

Volkwein, J.F. 2008. The Foundations and Evolution of Institutional Research. New Directions for Higher Education. 141:520. http://dx.doi.org/10.1002/he.289

Volkwein, J.F. 2011. Gaining Ground: The Role of Institutional Research in Assessing Student Outcomes and Demonstrating Institutional Effectiveness. National Institute for Learning Outcomes Assessment Occasional Paper 11, September 2011. Access online at http:// www.learningoutcomeassessment.org/ documents/Volkwein.pdf

Voorhees, R.A. 2008. Institutional Research's Role in Strategic Planning. New Directions for Higher Education. 141:7785. http://dx.doi.org/10.1002/he.295

Williford, A.M. 2009. Institutional Research in support of Student and Institutional Success, Ohio University Working Paper Series: CHEWP. 1:1-20. Access online at

https://www.ohio.edu/education/ centers-and-partnerships/centers/ center-for-higher-education/upload/ Institutional-Research-in-Support-ofStudent-and-Institutional-Success.pdf

Zechlin, L. 2010. Strategic Planning in Higher Education. In E. Baker, B. McGaw \& P. Peterson (eds.). International Encyclopedia of Education, 3rd Edition, Athens: Elsevier Ltd. pp. 1-15. http:// dx.doi.org/10.1016/B978-0-08-0448947.00885-X 